\title{
Assessing the applicability and usability of patient satisfaction levels as a tool for judging quality of service in a medical college hospital in Punjab, North India
}

\author{
Singh S. ${ }^{1 *}$, Verma V. ${ }^{2}$ \\ DOI: https://doi.org/10.17511/ijphr.2016.i5.02
}

\author{
1* Sumeet Singh, Senior Resident, Department of Community Medicine, Government Medical College, Patiala, Punjab, India. \\ $\mathbf{2}$ Verinder Verma, Assistant Professor, Department of Community Medicine, Government Medical College, Patiala, Punjab, India.
}

Introduction: Healthcare industries have seen recent movements towards continuous quality improvement at the global level. Patient satisfaction is one of the established yardsticks to measure success of the services being provided in the health facilities. Aims and objectives: 1) To review satisfaction rates among patients admitted in a Medical College hospital. 2) To evaluate applicability and usability of carrying out evaluation of patient satisfaction for hospital services as an indicator of quality of services. Material and Methods: A comparative review study of patient satisfaction rates was done in two phases, first in July- August, 2013 and then in March - April, 2015 among indoor patients being discharged admitted in major wards at Rajindra hospital (GMC Patiala). Results and Discussion: Most of the patients were from underserved sections of the community. Patients show higher satisfaction levels with the services and care provide by hospital staff. Regarding basic amenities, availability of toilets/hand washing facility in the wards, cleanliness in the toilets and wards, adequacy of Fans / Lights in the wards has been stated to be much improved by the patients but $72 \%$ respondents are claiming unavailability of drinking water. Patient satisfaction rates act as a reliable and rapid tool for assessing regular developmental activities and projecting the shortcomings to higher authorities. Conclusion \& Recommendations: Assessing satisfaction of patients is simple and cost effective way for evaluation of hospital services. Regarding applicability and usability of such patient satisfaction survey, we conclude that it must be incorporated in routine hospital functions.

Keywords: Patient satisfaction, Patient care, Hospital services, Hospital management, Quality of medical care

Corresponding Author

Sumeet Singh, Senior Resident, Department of Community Medicine, Government Medical College, Patiala, Punjab, India.

Email: 85.sumeet@gmail.com
How to Cite this Article

Singh S, Verma V. Assessing the applicability and usability of patient satisfaction levels as a tool for judging quality of service in a medical college hospital in Punjab, North India. Public Health Rev Int J Public Health Res. 2016;3(5):185-194. Available From https://publichealth.medresearch.in/index.php/ijphr/ To Browse

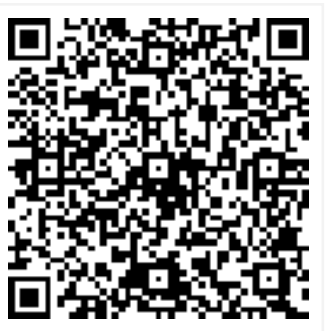
article/view/50 


\section{Introduction}

The primary goal of the tertiary care hospital as a highest level of health care provision is to provide best possible health care to the patients. The modern era where it is the right of every patient to demand best possible care in Government hospitals, it is the duty of every staff member of the hospital to deliver his optimum efforts to the entire satisfaction of the patient and its assessment will give us an opportunity to find loopholes in our services and future ratification.

It is the nature of a human being that by fulfilling one motive, another one takes the place which is to be fulfilled and the process goes on [1]. It helps in continuous evolution process. Healthcare industries have seen recent movements towards continuous quality improvement and this has gained momentum since 1990 and according to Donabedian's declaration for incorporating patient perception into quality assessment, healthcare managers thus incorporate patient centered care as a major component in the healthcare mission [2].

These trends are similar across the globe. The healthcare regulators shifted towards a marketdriven approach of turning patient satisfaction surveys into a quality improvement tool for overall organizational performance. In 1996, evaluation of patient satisfaction was made mandatory for all French hospitals. Laurent et al. 2006 conducted a study in a tertiary teaching hospital in France aiming to assess the opinions of clinical staff towards the effect of in-patient satisfaction surveys on the quality improvement process. A favorable result of $94 \%$ revealed that the patient was able to judge hospital service quality, especially in its relational, organizational and environmental dimensions.

In Germany, measuring satisfaction has been required since 2005 as an element of quality management reports. Since 2002, the Department of Health (DOH) has launched a national survey program in which all NHS trusts in England have to survey patient satisfaction on an annual basis and report the results to their regulators. Therefore, measurement of patient satisfaction is a legitimate indicator for improving the services and strategic goals for all healthcare organizations [2].

Patient satisfaction is one of the established yardsticks to measure success of the services being provided in the health facilities.
But it is difficult to measure the satisfaction and gauze responsiveness of the health systems as not only the clinical but also the non-clinical outcomes of care do influence the Patient satisfaction [3]. Satisfaction is a psychological concept which is defined in different ways. Sometimes satisfaction is considered as a judgment of individuals regarding any object or event after gathering some experience over time.

According to some theorists, satisfaction is a cognitive response whereas some others consider satisfaction as emotional attachment of individuals [4]. Human satisfaction is a complex concept that is related to a number of factors including lifestyle, past experiences, future expectations and the value of both individual and society [5].

The main beneficiary of a good health care system is clearly a patient. As a customer of healthcare, the patient is the focus of the health care delivery system. Patient's perceptions about health care system seem to have been largely ignored by the health care managers in the developing countries.

Patient satisfaction depends upon many factors such as: quality of clinical services provided, availability of medicine, behaviour of doctors and other health staff, cost of the services, hospital infrastructure, physical comfort, emotional support and respect for patient preferences [6]. For health care organization to be successful monitoring of customer's perception is a simple but important strategy to assess and improve their performance $[7,8]$.

Presently in India, especially in public health sector either no such mechanism is present to assess patient satisfaction or is in very crude form such as patient feedback forms which are not regularly compiled or analysed to have definite view. Very few studies had been carried out in India for measuring satisfaction of patient with hospital services.

Similarly, at Rajindra hospital which is a teaching tertiary care hospital attached with Govt. Medical College, Patiala; no regular mechanism of assessment of patient satisfaction exist and neither the administrative staff nor the teaching faculty is interested to know what their patients feel about quality of services in the hospital. Assessment of lacunas is based on hearsay information and selfperception of the limited persons in administrative staff. So, as a novel initiative present study was planned. 
The purpose of present study is to gauge the applicability and usability of assessing patient satisfaction as a tool for quality of services provision at the hospital by getting feedback from the respondents who have availed services as indoor patients based on a comprehensive study conducted at the medical college hospital in the state of Punjab. The main objective of this paper is to share the findings of this evaluation and present patient's satisfaction about various components of services.

\section{Aims and Objectives}

01. To review satisfaction rates among patients admitted in Govt. Medical College Rajindra hospital in terms of

- services provided by the doctors,

- nursing and paramedical care,

- laboratory services,

- availability of basic amenities.

02. To evaluate applicability and usability of carrying out evaluation of patient satisfaction for hospital services as an indicator of quality of services.

\section{Materials and Methods}

To achieve the objectives a comparative review study of patient satisfaction rates was planned. The assessment of patient satisfaction levels was conducted twice in two phases, first in July- August, 2013 and then in March - April, 2015 among patients admitted in wards of Medicine, General Surgery, Obstetrics \& Gynecology and Orthopedics departments at Rajindra hospital (GMC Patiala) with a minimum hospital stay of 24 hours, preferably who have completed the indoor stay and are going to be discharged within next 24 hours.

Permission for collecting reviews and recording in pre-structured performa was taken from medical superintendent of the hospital (Annexures $1 \& 2$ ). Study participants $(n=100)$ were randomly selected from patients being discharged during the study period. 25 patients were taken from every selected department. On the day of the discharge, after taking informed consent the patients were interviewed. A pre- designed pre- tested "Indoor Patient Feedback Form" was filled up. Factors affecting the patient satisfaction under study can be attributed to Acceptability, Accessibility, Patient centeredness, Competence, Appropriateness, Timeliness of treatment from patient's perspective.
After the first round in 2013, findings and conclusions of the study were sent to office of Medical Superintendent and Principal medical college about gaps in services perceived by patients and areas performing well in the hospital. Findings were also published in local media and also in a scientific journal. Luckily, during this period of around 2 years, lot of renovation of building, toilets, tiled floor, electric fittings and construction of new wings such as physiotherapy center and deaddiction center with grants from central govt.

Under the Pardhan Mantri Swasthya Suraksha Yojana have been done. A grant Rs.152 crore was provided to the hospital for renovation and construction of proposed new wings. Some of the wards have been provided with air conditioning also. Most of the wards now have shades and curtains in between the adjacent beds. 2nd round of survey was then conducted to assess the changes.

\section{Results}

Table 1 showed that most of the admitted patients in this govt. sector hospital belonged to weaker section of the society. The socio demographic profile of the patients sampled in 2013 is comparable to those studied in 2015. So, this shows there is not any apparent significant change in the type of patients availing services at this hospital in between the study period. More than half of the patients were either illiterate or have education up to primary level. Around $10 \%$ were unemployed and around $90 \%$ belong to socio-economic status of lower, upper lower and lower middle sections of society based on Kuppuswamy's scale. At least this much is the right of every human being which should be well considered and provided by the Government. The satisfaction levels of the studied patients in different aspects of hospital care areas described below.

Table-1: Socio- demographic profile $(n=100)$

\begin{tabular}{|l|l|l|}
\hline \multicolumn{2}{|c|}{2013} & 2015 \\
\hline Respondent & 51 & 46 \\
\hline a) Patient & 49 & 54 \\
\hline b) Attendant & 9 & 17 \\
\hline Age of the patient & 48 & 41 \\
\hline a) $<20$ & 29 & 33 \\
b) $21-40$ & 14 & 9 \\
\hline c) $41-60$ & \multicolumn{3}{|l|}{} \\
\hline d) $>60$ & 48 & 50 \\
\hline Sex/ Gender & 48 \\
\hline a) Male
\end{tabular}


Singh S. et al: Assessing the applicability and usability

\begin{tabular}{|c|c|c|}
\hline b) Female & 52 & 50 \\
\hline \multicolumn{3}{|l|}{ Residence } \\
\hline a) Urban & - & 45 \\
\hline b) Rural & - & 55 \\
\hline \multicolumn{3}{|c|}{ Duration of stay/admission } \\
\hline a) $<2$ days & 1 & 1 \\
\hline b) 2-5 days & 18 & 24 \\
\hline c) $>5$ days & 81 & 75 \\
\hline \multicolumn{3}{|l|}{ Education of patient } \\
\hline a) Illiterate & 44 & 41 \\
\hline b) Primary & 20 & 28 \\
\hline c) Matriculation & 22 & 14 \\
\hline d) Sen. Secondary & 9 & 9 \\
\hline e) Graduate & 5 & 8 \\
\hline \multicolumn{3}{|l|}{ Occupation of patient } \\
\hline a) Skilled & 23 & 18 \\
\hline b) Unskilled & 36 & 26 \\
\hline c) Unemployed & 10 & 8 \\
\hline d) Housewife & 28 & 39 \\
\hline e) Student & 3 & 9 \\
\hline \multicolumn{3}{|l|}{ Family Income/ month } \\
\hline a) < Rs. 2000 & 23 & \&nbdp; \\
\hline b) Rs. 2000- 5000 & 44 & \\
\hline c) Rs. $5000-10,000$ & 26 & \\
\hline d) > Rs. 10,000 & 7 & \\
\hline \multicolumn{3}{|c|}{ SES (Kuppuswamy's scale) } \\
\hline a) Lower & & 19 \\
\hline b) Upper lower & & 45 \\
\hline c) Lower middle & & 25 \\
\hline d) Upper middle & & 6 \\
\hline e) Upper & & 5 \\
\hline
\end{tabular}

Table 2 showed the perception (satisfaction levels) regarding services at the time of admission to the hospital of the patients which mostly were admitted through emergency and rest through outdoor. Most of them were satisfied in this aspect but still the areas needing attention are the sign boards showing direction and the time lapse between admission and initiation of treatment of more than 30 minutes in some of the cases and these are persisting on a similar pattern as found in the previous survey.

Although the patient's general perception indicates somewhat deterioration of services at admission process in aspects of helpfulness at registration and ward attendant / Support staff for assistance at entrance. However, rests of the attributes are similar in comparison except availability of wheel chairs / stretcher which has shown improvement.

Table-2 : Services available at Admission

\begin{tabular}{|l|l|l|}
\hline & 2013 & 2015 \\
\hline Mode of admission
\end{tabular}

\begin{tabular}{|c|c|c|}
\hline $\begin{array}{l}\text { a) Through emergency } \\
\text { b) Through outdoor }\end{array}$ & $\begin{array}{l}72 \\
28\end{array}$ & $\begin{array}{l}81 \\
19\end{array}$ \\
\hline \multicolumn{3}{|c|}{ Helpfulness of the person at Registration desk } \\
\hline a) Unsatisfactory & 4 & 9 \\
\hline b) Average & 26 & 12 \\
\hline c) Satisfactory & 62 & 77 \\
\hline d) Good & 8 & 2 \\
\hline \multicolumn{3}{|c|}{ Availability of Wheel chair / Stretcher } \\
\hline a) Available & 72 & 73 \\
\hline b) Not available & 11 & 2 \\
\hline c) Not required & 17 & 25 \\
\hline \multicolumn{3}{|c|}{ Ward attendant/ Support staff for assistance at entrance } \\
\hline a) Available & 88 & 79 \\
\hline b) Not available & 12 & 19 \\
\hline c) Not Required & 0 & 02 \\
\hline \multicolumn{3}{|l|}{ Ward location } \\
\hline a) Approachable & 96 & 93 \\
\hline b) Difficult to approach & 4 & 7 \\
\hline \multicolumn{3}{|l|}{ Sign Boards } \\
\hline a) Adequate \& helpful & 82 & 84 \\
\hline b) Inadequate & 18 & 16 \\
\hline \multicolumn{3}{|c|}{ Time taken between Admission and Initiation of treatment } \\
\hline a) Immediate & 20 & 46 \\
\hline b) $<10$ mins & 51 & 27 \\
\hline c) $10-30 \mathrm{mins}$ & 16 & 15 \\
\hline d) $>30$ mins & 13 & 12 \\
\hline
\end{tabular}

Table-3: Perception of Quality of Professional service by Doctors

\begin{tabular}{|c|c|c|}
\hline & 2013 & 2015 \\
\hline \multicolumn{3}{|c|}{ Time devoted by the Doctor at the time of admission } \\
\hline a) Adequate & 94 & 97 \\
\hline b) Inadequate & 6 & 3 \\
\hline \multicolumn{3}{|c|}{ Description of disease status by Doctor } \\
\hline a) Adequate/ Satisfactory & 87 & 93 \\
\hline b) Inadequate/ Unsatisfactory & 13 & 7 \\
\hline \multicolumn{3}{|l|}{ General communication of Doctor } \\
\hline a) Good/ Pleasant & 56 & 62 \\
\hline b) Satisfactory & 32 & 38 \\
\hline c) Unsatisfactory & 12 & 0 \\
\hline \multicolumn{3}{|c|}{ Perception of Efficiency of Doctors in handling patients } \\
\hline a) Satisfactory & 91 & 97 \\
\hline b) Unsatisfactory & 9 & 3 \\
\hline \multicolumn{3}{|c|}{ Doctors discussed Lab investigation with Patient } \\
\hline a) Satisfactory & 84 & 92 \\
\hline b) Unsatisfactory & 16 & 8 \\
\hline \multicolumn{3}{|c|}{ No. of visits of senior doctors/ consultants } \\
\hline a) Satisfactory & 74 & 94 \\
\hline b) Unsatisfactory & 26 & 6 \\
\hline
\end{tabular}

Table 3 shows apparent enhancement in perception of the patients regarding quality of professional service by doctors at the hospital in almost all the 
Attributes studied indicating higher levels of satisfaction with the functioning of the doctors. No. of visits of senior doctors/consultants, which previously was a deficient area has shown significant improvement in patient's perception. It was good to find the perception of the patients about the efficiency of doctors in handling their illness.

The findings in the Table 4 interpret a good satisfaction levels with the services provided at the laboratories of the hospital and there has been a significant improvement even in the problem areas identified in 2013 such as difficulty to locate the labs and time taken to reach the labs for investigations which was 10-30 mins in $71 \%$ of cases and more than 30 mins in some of the cases. Improvements in providing results / reports of investigations in timely manner are a good indicator of efficiency in handling laboratory work despite large no. of OPD and Indoor patients.

\section{Table-4: Perception of Quality of Laboratory} services

\begin{tabular}{|c|c|c|}
\hline & 2013 & 2015 \\
\hline \multicolumn{3}{|c|}{$\begin{array}{l}\text { Have you been told about the location / room no./ department where } \\
\text { investigations were advised }\end{array}$} \\
\hline a) Yes & 91 & 93 \\
\hline b) No & 9 & 7 \\
\hline \multicolumn{3}{|l|}{ Location of Labs for investigations } \\
\hline a) Easily approachable / locatable & 73 & 93 \\
\hline b) Difficult to locate/ Approach & 27 & 7 \\
\hline \multicolumn{3}{|c|}{ Time to reach lab/ department for investigations } \\
\hline a) $<10 \mathrm{mins}$ & 22 & 80 \\
\hline b) $10-30$ mins & 71 & 19 \\
\hline c) $>30$ mins & 7 & 1 \\
\hline \multicolumn{3}{|l|}{ Availability of Lab Technician } \\
\hline a) Yes & 98 & 99 \\
\hline b) No & 2 & 1 \\
\hline \multicolumn{3}{|l|}{ Approach of Lab Technician } \\
\hline a) Satisfactory & 89 & 96 \\
\hline b) Unsatisfactory & 11 & 4 \\
\hline \multicolumn{3}{|l|}{ Availability of Investigations results } \\
\hline a) Available on scheduled time & 84 & 99 \\
\hline b) Delayed & 16 & 1 \\
\hline
\end{tabular}

Satisfaction levels regarding quality of service by nursing and paramedical staff in the patients were also found to be high as most of the patients were satisfied with the availability, communication / behaviour of nurses and paramedical staff in the wards during admission. Most of the patients affirmed that they were provided medication in timely manner by the nurses and rated
Communication / behaviour of the nurses as good / pleasant and satisfactory in $23 \%$ and $59 \%$ of the cases respectively in 2013 and this aspect has improved more. Now less of the respondents described their behaviour as harsh/ rude/ avoiding which can be a motivation for the staff working in the hospital. Slight decrement has been noticed in approach of other paramedical staff towards patients/ attendants which can be looked into and training could be provided to the other paramedical staff.

Table-5: Perception of quality of service by Nursing and paramedical staff

\begin{tabular}{|c|c|c|}
\hline & 2013 & 2015 \\
\hline \multicolumn{3}{|c|}{ Availability of Nursing staff in the wards } \\
\hline a) Adequate & 98 & 98 \\
\hline b) Inadequate & 2 & 2 \\
\hline \multicolumn{3}{|c|}{ Communication/ behaviour of Nursing staff towards patient } \\
\hline a) Good/ Pleasant & 23 & 29 \\
\hline b) Satisfactory & 59 & 68 \\
\hline c) Harsh / Rude & 12 & 3 \\
\hline d) Avoiding & 6 & 0 \\
\hline \multicolumn{3}{|c|}{ Dispensing/ Providing prescribed medications in timely manner } \\
\hline a) Yes & 83 & 87 \\
\hline b) No, Has to be asked & 12 & 4 \\
\hline c) Not known & 5 & 9 \\
\hline \multicolumn{3}{|c|}{ Availability of Para medical Staff to the Patients } \\
\hline a) Adequate & 82 & 86 \\
\hline b) Inadequate & 18 & 14 \\
\hline \multicolumn{3}{|c|}{ Approach of other Paramedical staff towards patients/ attendants } \\
\hline a) Satisfactory & 97 & 85 \\
\hline b) Unsatisfactory & 3 & 15 \\
\hline \multicolumn{3}{|c|}{ Quality of Health care / Support provided by Para medical staff } \\
\hline a) Satisfactory & 81 & 81 \\
\hline b) Unsatisfactory & 19 & 19 \\
\hline
\end{tabular}

Table-6: Perception regarding availability of basic amenities

\begin{tabular}{|l|l|l|}
\hline \multicolumn{2}{|c|}{2013} & 2015 \\
\hline Availability / Provision of Medicines by Hospital & 19 & 12 \\
\hline a) Available & 56 & 41 \\
b) Unavailable & 25 & 47 \\
c) Very few & 36 & 12 \\
\hline Availability of Oxygen Cylinders during admission & 1 \\
\hline a) Available & 9 & 0 \\
b) Unavailable & 12 & 87 \\
\hline c) Very few & 43 & 28 \\
d) Not required & 79 & 72 \\
\hline Availability of Drinking Water In the premises \\
\hline a) Available & 21 & \\
b) Unavailable & 79 \\
\hline Availability of toilet / Handwashing facility in the wards
\end{tabular}




\begin{tabular}{|c|c|c|}
\hline $\begin{array}{l}\text { a) Yes } \\
\text { b) No }\end{array}$ & $\begin{array}{l}57 \\
43\end{array}$ & 91 \\
\hline \multicolumn{3}{|l|}{ Toilets well maintained / Cleaned by Staff } \\
\hline a) Yes & 38 & 62 \\
\hline b) No & 62 & 38 \\
\hline \multicolumn{3}{|l|}{ Cleanliness in the wards } \\
\hline a) Satisfactory & 60 & 83 \\
\hline b) Unsatisfactory & 40 & 17 \\
\hline \multicolumn{3}{|l|}{ Availability of Fans / Lights In wards } \\
\hline a) Adequate & 66 & 97 \\
\hline b) Inadequate & 34 & 3 \\
\hline \multicolumn{3}{|c|}{ Availability/ Regular change of bed sheets } \\
\hline a) Available on scheduled time & 20 & 62 \\
\hline b) Delayed & 44 & 17 \\
\hline c) Not available & 29 & 2 \\
\hline d) Available but not usable/ unclean & 7 & 19 \\
\hline \multicolumn{3}{|l|}{ Convenience of parking } \\
\hline a) Good & 5 & 8 \\
\hline b) Satisfactory & 21 & 52 \\
\hline c) Unsatisfactory & 44 & 13 \\
\hline d) Not required & 30 & 27 \\
\hline \multicolumn{3}{|l|}{ Meals available / provided in the ward } \\
\hline a) Yes & 18 & 20 \\
\hline b) No & 82 & 80 \\
\hline If Yes, Quality of food provided & $n=18$ & $n=20$ \\
\hline a) Satisfactory & 16 & 20 \\
\hline b) Unsatisfactory & 2 & 0 \\
\hline \multicolumn{3}{|c|}{ Availability of Retiring / Waiting room for relatives/ attendants } \\
\hline a) Available & 0 & 14 \\
\hline b) Unavailable & 100 & 86 \\
\hline
\end{tabular}

Regarding the availability of basic amenities and services at the hospital as shown in Table 6 there is much scope of improvement, as unavailability of essential medicines is still a weaker area despite being raised at multiple forums and even in this study in 2013. Situation of unavailability of drinking water has worsened as now $72 \%$ respondents are claiming unavailability of drinking water. Rest of the aspects like availability of toilets / hand washing facility in the wards, cleanliness in the toilets and wards, adequacy of Fans / Lights in the wards has been stated to be much improved by the patients.

Patients are now more satisfied with the timely change of bed sheets. Dissatisfaction with the convenience of parking has also decreased. But provision of meals to the patient remains neglected as this is recurring type of expenditure and requires continuous support. Only $20 \%$ of the patients got meals, most of them were pregnant ladies in the obstetrics ward and were provided meals under JSSK and some others got from meals provided by some NGO and religious organizations.
Unavailability of retiring room for the attendants / relatives of the patient is another setback for the caregivers and family of the patient.

\section{Discussion}

During both the phases of this study in 2013 \& 2015, socio demographic profile of the patients remained similar and most of the patients availing service belong to socio-economically weaker sections of the society. This needy section of the society does not have large expectations from the hospital besides their medical treatment and provision of basic amenities during the stay at hospital. It was good to find that the patients have good faith in their doctors and are sure about efficiency of doctors in handling their illness.

The delay and difficulty in reaching the labs found in first phase in 2013 which was due to absence of sign boards and in some of the cases samples have to be taken to some of the departments like pathology and microbiology situated in medical college building on other side of the road, have been duly taken care by the hospital authorities and now most of the samples (at scheduled times) are collected by hospital staff from the wards and moreover the Lab premises and sample collection center of the Biochemistry department has been shifted to hospital premises.

This is the reason behind apparent enhancement in satisfaction rates for the laboratory work. This change has also helped the lab workers and hospital staff, which is also evident in their timeliness of providing lab results. This can be further enhanced through adequate sign boards indicating direction of departments and room no. of designated labs at the entrance gate of the hospital. Patients are also satisfied up to a larger extent with service provision by staff nurses and other paramedical staff, which might not be so upright but fulfills the expectations of the patients.

Although much improvement in patient satisfaction can be seen in the area of provision of basic amenities but these are most important areas to be considered as these are quite apparent, represents the managerial abilities of hospital administrators because other things like staffing and medical care are much complicated in public sector hospital. Moreover they present the face of the hospital, determine the clientele of the hospital and their provision is a must for patient and attendants to allay problems to those who are already suffering. 
Provision of essential medicines despite various measures by State govt. is still a weaker area. It was reported in the first phase (2013) also and since then Punjab Govt. has prepared a list of essential medicine to be provided at every level of health care delivery system but due to hierarchical and structural gaps as medical college hospital are working as a separate unit under department of medical education and research, is lacking in regular availability. Situation of unavailability of drinking water has worsened which is of grave concern and should be immediately handled because patient and attendants are forced to purchase packaged water or collect water from far-off locations.

With the provision of funds and renovations facilities like availability of toilets/hand washing facility in the wards, cleanliness in the toilets and wards, adequacy of Fans /Lights in the wards has much improved as perceived by the patients. Repair of the floor has been done to tiled flooring and usage of automated floor mopes has been started. Similar problems have also been found by Kulkarni et al in 2008. Level of satisfaction among patients was found to be better with behaviour of doctors $(87.76 \%)$. Dissatisfaction was found to be more with cleanliness in toilets $(56.01 \%)$ as compared to the other hospital areas which was also statistically highly significant [9].

Parking problem although improved since first phase but had rightly identified by this survey as Hospital administration is also aware of this issue and has proposed for a multi-story parking facility to be constructed. Provision of meals is an issue out of the hands of the hospital administration but remains neglected as this involves recurring type of expenditure and requires continuous support from the govt. This need of the patients is being compensated by some NGOs and Gurdwara committees. Unavailability of retiring room for the attendants / relatives of the patient is another setback for the caregivers and family of the patient.

Sequential surveys are thus helpful in comparing the situation and judge impact of structural and functional improvements. Similar were the findings by Niles et al in cardiology patients using patient satisfaction surveys as a tool for finding the scope for improvement [10].

\footnotetext{
Applicability and Usability of Patient satisfaction surveys at this hospital as a tool for Quality of service.
}

As presently no such system of regular collection of responses from patients and analyzing patient satisfaction rates is there in this hospital. So to suggest whether such kind of exercise will be beneficial to this hospital and should be done as a regular practice, we have to learn from experiences from these two phases.

01. Present study successfully depicts improvements in patient satisfaction rates in areas where renovation and reforms activities have been done. Easy to represent benefits in areas where Cost- Benefit analysis are difficult to perform. e.g. electric fitting repairs, bathroom repairs.

02. Successfully acts as a rapid assessment tool.

03. Had easily identified lacking areas like drinking water unavailability.

04. Reliable tool for projecting the shortcomings to higher authorities and press on for regular developmental activities.

05. Improved satisfaction of the patients regarding service and care provided by the doctors and hospital staff if effectively used can act as a motivational factor for continuous improvement and motivation of the staff.

06. Although present studies have been done as a cross- sectional one using random sampling but are able to represent the existing gaps in the service delivery.

07. As a tool for judging the benefits of managerial decisions e.g. shifting of biochemistry laboratory to hospital premises and location where new shed have been installed by Red-Cross for relatives.

08. As a public sector hospital it is catering to a large population which is dependent on this hospital for its medical needs, regular patient satisfaction assessments can be used in gaining political will for proposed improvements showing previous expenditure was able to raise patient's faith and improve satisfaction.

09. Possible to identify the weaker departments of the hospital by separately analyzing satisfaction rates of different departments.

10. It does not involve much cost, moreover if staff is deficient, this work can be done intermittently through sampling. 
So, it can be said that patient satisfaction is an important quality outcome indicator to measure success of the services delivery system. Evaluation of care by patients is important to provide opportunity for improvement such as structural reforms, strategic framing of health plans, which sometimes exceed patient expectations and benchmarking. But the efficiency in patient satisfaction surveys rely heavily on using standardized, psychometrically tested data collection approaches. Regarding applicability and usability of such patient satisfaction survey, author is of definite opinion that it must be incorporated in routine hospital functions because of the above found benefits and no such negative factor has been found to suggest any risks associated with it.

A review of patient satisfaction surveys in Pakistan also concludes that prompt attention to patients' expectations, enhancing responsiveness of health care system and consideration of patient's perceptions is of utmost importance to increase patient satisfaction outcomes [11]. Sajid et al in their study opines that Service characteristics effecting patient's perception of quality should be included while designing service. Majority of patients in public sectors hospitals are from lower income groups, service characteristics should be targeted toward lower income rather than elites [12].

\section{Conclusions \& Recommendations}

Assessing satisfaction of patients is simple and cost effective way for evaluation of hospital services. The findings of the present reveal that patients were more satisfied with behavior and function of doctors and staff. But problem lies with the availability of basic amenities and dissatisfaction was found to be more regarding provision of essential medicines, drinking water, retiring room and parking issues. These are some urgent issues needing concern. Regarding applicability and usability of such patient satisfaction survey, we conclude that it must be incorporated in routine hospital functions.

\section{Limitations}

This is only a baseline study with a small sample as it was a self - funded project. A continuous ongoing process of evaluating the services at the time of discharge is required for getting definitive results.
We believe the scores obtained from the present study can serve as baseline against which to compare the results from future surveys.

\section{Reference}

01. Khandelwal A. Human Resource Development. Oxford and IBH, New Delhi. 1988.

[Crossref]

02. Rashid Al-Abri, Amina Al-Balushi. Patient Satisfaction Survey as a tool towards Quality Improvement. Oman Medical Journal. 2014;29(1)3-7.

[Crossref]

03. Agrawal D. Health sector reforms- Relevance in India. Indian J Community Med. 2006;31(4)220-22.

[Crossref]

04. Chakraborty R, MajumdarA. Measuring consumer satisfaction in health care sector- The applicability of SERVQUAL. International Referred Research Journal. 2011;II(4)150.

Available at: [Article] [Crossref]

05. Verma A, Sarma RK. Evaluation of the exit proformas in use at special wards of public sector tertiary care center. Journal of Academy of hospital administration. 2000;12(1)1-6.

[Crossref]

06. Jenkinson C, Coulter A, Bruster S, Richards N, Chandola T. Patient's experiences and satisfaction with healthcare- Results of a questionnaire study of specific aspects of care. Qual Saf Health Care. 2002 Dec; 11(4)335-9. [Crossref]

07. Bhattacharya A, Menon P, Koushal V, Rao KLN. Study of patient satisfaction in a tertiary referral hospital. Journal of the academy of hospital administration. 2003-01-2003-06)15(1). [Crossref]

08. Singh B, Sarma R K, Sharma D K, Singh V A, Sanjay $D$. Assessment of hospital services by consumers- A study from NDDTC, AIIMS, Ghaziabad. Medico legal update. 2005;5(1). [Crossref]

09. Kulkarni MV, Dasgupta S, Deoke AR, Nayse. Study of Satisfaction of Patients Admitted in a Tertiary Care Hospital in Nagpur. National journal of Community Medicine. 2011;2(1)37-9. [Crossref] 
10. Niles N, Tarbox G, Schults W, Swartz W, Wolf E, Robb J, et al. Using qualitative and quantitative patient satisfaction data to improve the quality of cardiac care. Jt Comm J Qual Improv. 1996 May;22(5)323-35.

[Crossref]

11. Naseer M, Zahidie A, Shaikh BT. Determinants of patient's satisfaction with health care system in Pakistan- a critical review. Pakistan Journal of Public Health. 2011;2(2)52-61.

[Crossref]
12. Sajid A, Ali $H$, Rashid $M$, Raza A. Impact of process improvement on patient satisfaction in public health care facility in Pakistan, Proceedings of the 11th Quality Management and Organizational Development (QMOD) Conference; 2008 Aug 20-22; Helsingborg. Sweden- Linköping University Electronic Press. 2008.

Available from: [Article] [Crossref] 